\title{
ДОСЛІДЖЕННЯ СОРБЦЙНИХ ТА КІНЕТИЧНИХ ВЛАСТИВОСТЕЙ СОРБЕНТІВ НА ОСНОВІ ОКСИГІДРОТОВАНИХ ІОНІВ ЦИРКОНІЮ, АЛЮМІНІЮ, ЗАЛІЗА, МАРГАНЦЮ ДЛЯ ОЧИЩЕННЯ ПИТНОЇ ВОДИ
}

\author{
Г.В. Дзюба, Л.М. Гагаріна \\ Криворізький технічний коледж Національної металургійної академії Украӥни \\ вул. Степана Тільга, 40, Кривий Ріг, 50103, Україна \\ e-mail: dzyuba.ganna@gmail.com
}

Загрозою для всього людства вважається виснаження і погіршення якості водних ресурсів. Через 30 років половина населення Землі страждатиме від нестачі води. Для України цей час може настати значно раніше, а для жителів 1228 міст, населених пунктів, що користуються привізною водою, він уже настав. На сьогодні в Україні практично немає поверхневих водойм, які за ступенем забруднення води, екологічним станом і основними санітарно-хімічними та мікробіологічними показниками можна було б віднести до водойм першої категорії, з яких можна приготувати чисту питну воду.

Високий рівень техногенного навантаження на водойми, використання застарілих технологій водопідготовки, недостатньо ефективні коагулянти призводять до надходження до питної води значної кількості неорганічних і органічних забруднювачів, які негативно впливають на здоров'я. Сучасні методи очищення води від шкідливих домішок недостатньо ефективні. Дуже перспективним для очищення різних середовищ є застосування сорбційних матеріалів. Під сорбційним очищенням води розуміють сорбцію речовин на поверхні або в об'ємі пор твердого матеріалу.

Сорбційні матеріали здатні ефективно поглинати іони важких металів за рахунок поверхневої адсорбції внаслідок різних міжмолекулярних та іонних взаємодій.

Однак поглинальні властивості різних видів сорбентів дуже відрізняються в залежності від складу, способу отримання та обробки матеріалу. Визначення оптимального складу та методу одержання сорбенту, підвищення селективності за рахунок введення домішок, та вплив цих параметрів на його фізико-хімічні властивості є дуже актуальною проблемою. Це пов'язано насамперед 3 необхідністю доочищення питної води від іонів важких металів при умові збереження оптимального водно-сольового балансу.

Метою даної роботи є визначення основних властивостей сферогранульованого сорбенту на основі оксигідроксиду цирконію 3 домішками оксигідроксидів заліза, алюмінію та марганцю [1].

Методи дослідженні - фотоколориметрія, хімічні методи аналізу, гравіметрія, термодинамічні та кінетичні розрахунки.

Для дослідження основних властивостей сорбентів, за допомогою золь-гель технології були отримані лабораторні зразки сорбентів різного хімічного складу. Перевагами даних сорбентів на відміну від іонообмінних смол $є$ те, що вони не сорбують іони кальцію та магнію, 
які активно приймають участь в біологічних процесах, має високі температурні режими, та $є$ стійкими при роботі в агресивних середовищах.

В ході дослідження вологи в сорбентах (рис. 1), було встановлено що волога активно видаляється в перші 3 години, що свідчить про наявність вільної вологи. Загальний вміст вологи в сорбентах становить 17-25\%, що говорить про те, що отримані гранули сорбенту мають розвинену структуру пор. У сорбентах на основі оксигідроксидів алюмінію і марганцю зі збільшення мольного співвідношення іонів марганцю збільшується вміст вільної вологи, що дає можливість зробити припущення про те, що при введення оксигідроксиду марганцю утворюється більш пориста внутрішня структура зерна.

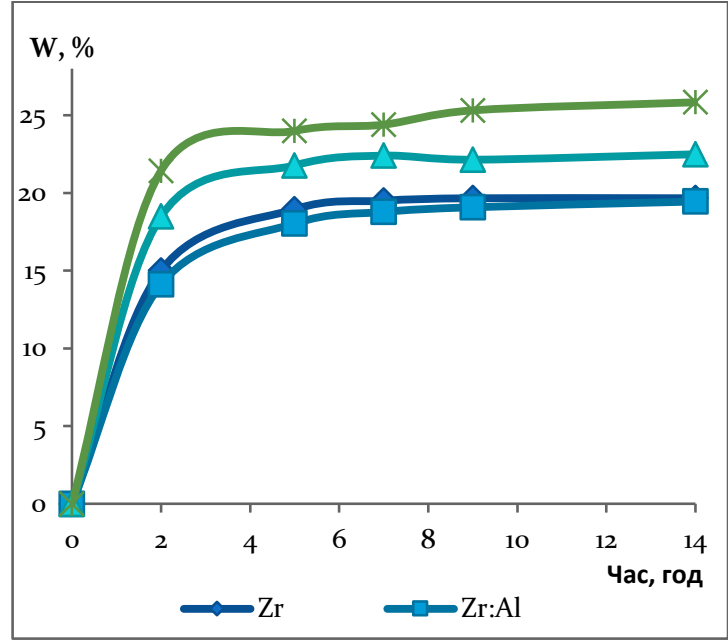

$\mathrm{a}$

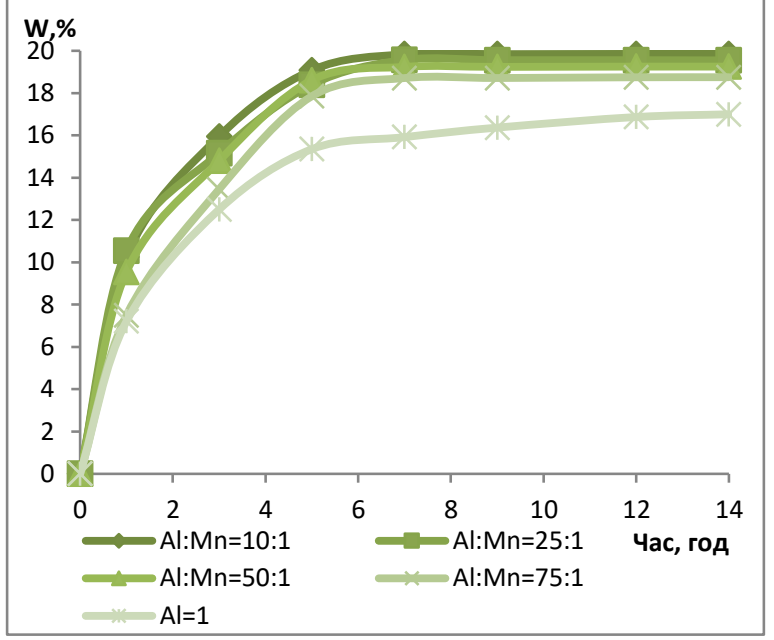

б

Рисунок 1. Залежності видалення вологи а - сорбенти на основі ОГЦ; б - сорбенти на основі ОГА

Визначення сорбційних властивостей іонів заліза (III), марганцю (II), фосфат-іонів проводилося шляхом побудови ізотерм сорбції (рис. 2), та кількісного визначення досліджуваних іонів відповідними методами аналітичної хімії [2,3].

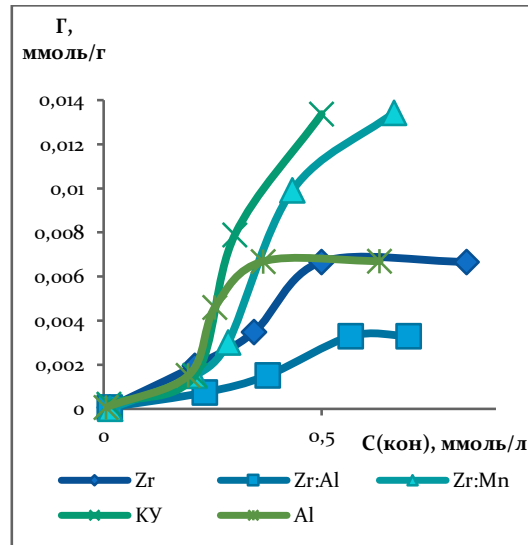

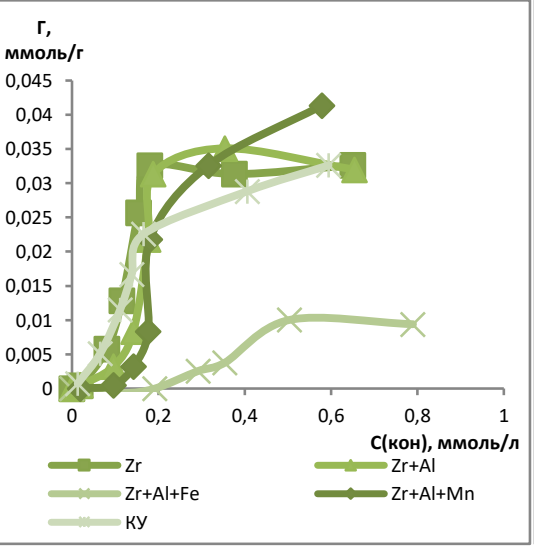

б

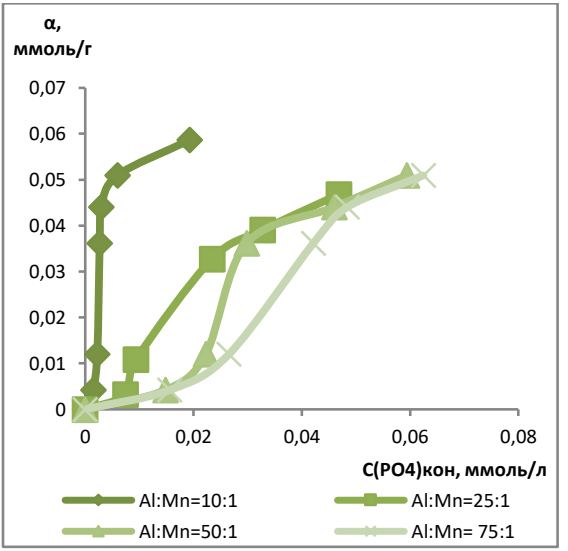

B

Рисунок 2. Ізотерми сорбції а-іонів заліза, б - іонів марганцю, в - фосфат - іонів 
Сорбенти на основі оксигідроксидів цирконію і алюмінію в 3-6 рази перевищують сорбційну ємність промислового аніоніта АН-221. За сорбційної ємністю іонів натрію сорбенти на основі оксигідроксиду цирконію не поступаються промисловому катіонітів КУ-2, а сорбенти на основі оксигідроксиду алюмінію перевищують в 4 рази. Таким чином встановлено, що досліджувані сорбенти мають амфолітні властивості, тобто можуть виступати як катіонітом, так і аніонітом. Найбільш ефективно в якості іоніта виступають сорбенти $з$ домішками оксигідроксидів марганцю.

3 представлених ізотерм сорбції видно що вони мають $\mathrm{S}$ - подібну форму, яка означає, що накопичення кінцевого продукту відбувається з прискорення [4]. Можна припустити, що в початковий момент часу відбувається накопичення мономолекулярного шару за рахунок фізичних взаємодій, а потім відбувається основний процес сорбції викликаний хімічними взаємодіями.

Кінетику процесу сорбції вивчали за допомогою кінетичних залежностей (рис. 3). Основний процес сорбції іонів заліза відбувається в перші 8 годин, а встановлення рівноваги в системі сорбат-сорбент встановлюється протягом 24 годин. 3 залежності видалення іонів марганцю видно, що для його видалення необхідно 5 годин. 3 кінетичної залежності фосфат іонів видно, що на видалення фосфат іонів витрачається 3 години.

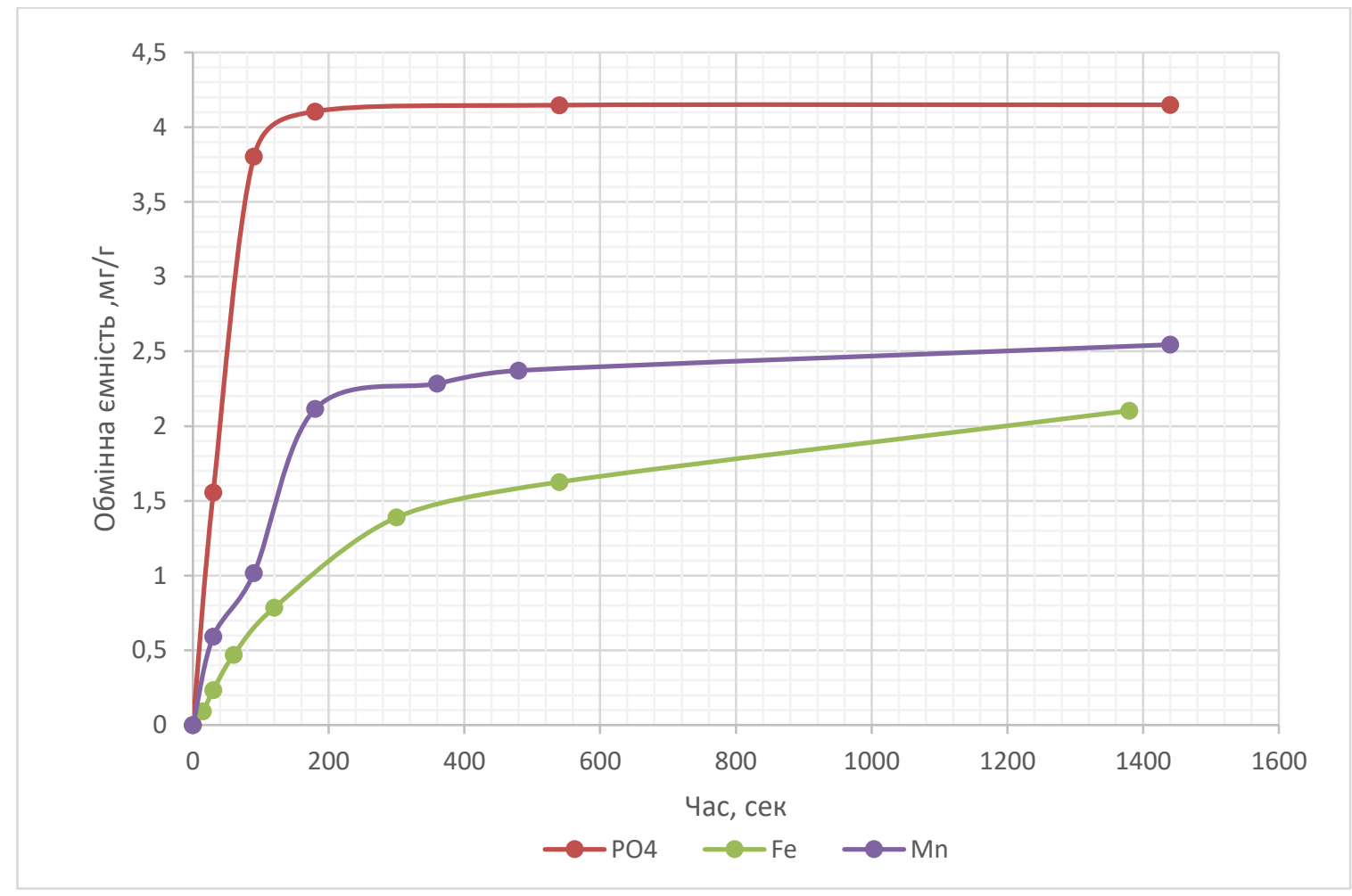

Рисунок 3. Кінетичні залежності виділення іонів заліза, марганцю та фосфат-іонів

Для визначення лімітуючої стадії отримані ізотерми були оброблені за допомогою моделей Бойда, псевдо-першого i псевдо-другого порядку[5-8]. Отримані константи рівнянь i ï коефіцієнти детермінації наведені в таблиці 1. 
Таблиця.

\section{Коефіціснти кінетичних моделей}

\begin{tabular}{|c|c|c|c|c|c|c|c|c|c|}
\hline \multicolumn{2}{|c|}{$\begin{array}{c}\text { Константи } \\
\text { зовнішньої } \\
\text { дифузії }\end{array}$} & \multicolumn{2}{|c|}{$\begin{array}{c}\text { Константи } \\
\text { внутрішньої } \\
\text { дифузії }\end{array}$} & \multicolumn{3}{|c|}{$\begin{array}{c}\text { Модель псевдопершого } \\
\text { порядку }\end{array}$} & \multicolumn{3}{|c|}{$\begin{array}{c}\text { Модель псевдо другого } \\
\text { порядку }\end{array}$} \\
\hline $\mathrm{k}, \mathrm{c}^{-1}$ & $\mathrm{R}^{2}$ & $\mathrm{k}, \mathrm{c}^{-1}$ & $\mathrm{R}^{2}$ & $\mathrm{k}_{1}, \mathrm{XB}^{-1}$ & $\begin{array}{c}\mathrm{q}_{\mathrm{e}}, \\
\text { моль } / \Gamma\end{array}$ & $\mathrm{R}^{2}$ & $\begin{array}{c}\mathrm{k}_{2}, \\
\Gamma / \text { Ммоль } \cdot \mathrm{XB}\end{array}$ & $\begin{array}{c}\mathrm{q}_{\mathrm{e}}, \\
\text { моль/г }\end{array}$ & $\mathrm{R}^{2}$ \\
\hline \multicolumn{10}{|c|}{ Для сорбції іонів заліза } \\
\hline 0,0036 & 0,997 & 0,006 & 0,988 & 0,0006 & 0,037 & 0,997 & 0,082 & 0,044 & 0,998 \\
\hline \multicolumn{10}{|c|}{ Для сорбції іонів марганцю } \\
\hline 0,005 & 0,910 & 0,008 & 0,982 & 0,0017 & 0,0914 & 0,973 & 0,2839 & 0,0495 & 0,991 \\
\hline \multicolumn{10}{|c|}{ Для сорбції фосфат-іонів } \\
\hline 0,013 & 0,912 & 0,02 & 0,992 & 0,021 & 0,017 & 0,984 & 1,48 & 0,044 & 0,998 \\
\hline
\end{tabular}

Для всіх зразків кінетичні залежності описують внутрішньодифузійний процес сорбції на початкових ділянках, однак коефіцієнт детермінації для моделей зовнішньодифузійного процесу відрізняється незначною мірою та ймовірністю всього в початковий момент часу, що виникає у процесі змішаного дифузійного процесу, а лімітуюча стадія є хімічна взаємодія, яка описується моделлю псевдо другого порядку.

Порівнюючи всі досліджувані властивості видно, що сорбенти, отримані в лабораторних умовах, нічим не поступаються промисловому катіоніту КУ-2 і перевищують сорбційні властивості промислового аніоніта АН-221. Можна зробити висновок про доцільність запровадження в якості домішок оксигідроксидів алюмінію і марганцю. Так як отримані зразки перевищують сорбційну ємність іонів марганцю, сульфат-іонів і фосфат - іонів та не поступаються по сорбції іонів натрію і заліза в порівнянні 3 промисловими зразками. Досліджуючи термодинамічні властивості встановлено, що сорбція протікає на неоднорідній поверхні, так як описується рівнянням Фрейндліха. При дослідженні кінетики встановлено, що найменший час витрачається для видалення фосфатів та іонів марганцю. Процес сорбції описується змішанодифузійною і хімічною взаємодією.

\section{Лiтература:}

1. Dun Hiu-Juan, Wei Yu, Song Xiu-Qin, Chen Li-Ren. Поверхностные свойства сорбентов на основе диоксида циркония для високоэффективной жидкостной хроматографии //Chem. J. Univ. - 2005. - 26. - №11. -2500 c.

2. Швоева О.П., Дедкова В.П., Гитлиц Л.Г., Саввин С.Б.. // Журнал аналитической химии. -1997 - Т.52, - 890 c.

3. Морозко С.А., Иванов В.М.. // Журнал аналитической химии. - 1995 - Т 50 - 629 с.

4. А.П. Карнаухов, Адсорбция, текстура дисперсных и пористых материалов. Новосибирск, «Наука». - 1999. - $786 \mathrm{cl}$

5. Романцова И.В., Бураков А.Е., Кучерова А.Е. //Изучение кинетики процесса жидкофазной сорбции органических веществ на гибридных наноструктурированих углеродных сорбентах, Тамбов, 2014

6. Abasi C.Y., Abai A.A., igwe J.C.// Adsorption of Iron, Lead, Cadmium ins by Unmodified Raphia Palm Fruit Endocarp, Nigeria, 2011

7. Крижановская О.О., Сияева Л.А., Карпов С.И. // Кинетические модели при описании сорбции жирорастворимых физиологически активных веществ высокоупорядоченными неорганическими кремнейсодержащими материалами, Воронеж, - 2014

8. Тимофеев К.Л., Усольцев А.В., Набойченко С.С., Мальцев Г.И. // исследование кинетики совмесной сорбции индия и железа на полифункциональном катионите, Омкс, Вести №3, 2015. 